\title{
Health literacy and numeracy: Key factors in cancer risk comprehension
}

\author{
L Donelle, RN, PhD (1); J. F. Arocha, PhD (2); L Hoffman-Goetz, PhD, MPH (2)
}

\begin{abstract}
In this age of chronic disease and shared decision making, individuals are encouraged to contribute to decisions about health care. Health literacy, including numeracy, is requisite to meaningful participation and has been accepted as a determinant of health. The purpose of this study was to describe the influence of literacy, consisting of prose and numeracy skill, math anxiety, attained education and context of information on participant ability to comprehend Internet-based colorectal cancer prevention information. Prose, numeracy, and math-anxiety data, as well as demographic details, were collected for 140 Canadian adults, aged $50+$ years. Participants had adequate prose literacy (STOFHLA) scores, high STOFHLA numeracy scores, moderate levels of health-context numeracy, poorer generalcontext numeracy and moderate math anxiety. There was better comprehension by participants of common (9.14/11) compared with uncommon (7.64/11) colorectal cancer information $(p<0.01)$. Prose literacy, numeracy, math anxiety and attained education accounted for $60 \%$ of the variation in participant comprehension scores. Numeracy, ranging from basic to advanced proficiency, is required to understand online cancer risk information. Prose literacy enhances numeracy when the subject matter is less familiar. These findings highlight the importance of presenting Web-based information that accommodates diverse health literacy and numeracy levels.
\end{abstract}

Key words: communication, risk, Internet, neoplasms, health literacy, numeracy

\section{Introduction}

Health literacy is essential to understanding health information and is defined as "the degree to which individuals have the capacity to obtain, process, and understand basic health information and services needed to make appropriate health decisions." Furthermore, the Public Health Agency of Canada identifies literacy as an important determinant of health. ${ }^{2}$ Yet, many adults are limited in prose health literacy and health numeracy skill. In particular, more older than younger adults demonstrate poor literacy skills. ${ }^{3-14}$ Estimates of inadequate or marginal health literacy among seniors range from $34 \%$ of individuals aged 65 years and older ${ }^{4,7,14}$ to $81 \%$ of individuals 60 years and older. ${ }^{13}$ Inadequate health literacy skill has been identified as an important barrier for seniors to understand diagnoses and treatment protocols. ${ }^{13-15}$

Until recently, health literacy has been portrayed mainly as a reading comprehension skill with health numeracy attracting little research attention. ${ }^{16}$ Health numeracy is "the degree to which individuals have the capacity to access, process, interpret, communicate, and act on numerical, quantitative, graphical, biostatistical and probabilistic health information needed to make effective health decisions." 16 Published accounts of numeric competency within health care settings indicate inadequate numeracy skills among young,17,18 and older adults. ${ }^{12,19}$ Cancer patients with decreased numeracy skills may have a diminished ability to accurately assess and personalize health risks. ${ }^{10,17,20}$

Colorectal cancer is the fourth leading cause of cancer among Canadians and the second leading cause of cancer deaths. ${ }^{21}$ Further increases in incident colorectal cancers are anticipated resultant to an aging population. ${ }^{21}$ Although colorectal cancer screening programs have been introduced in select provinces, to date a national colorectal cancer screening program has not been implemented in Canada. Consequently, health education and patient vigilance regarding risk awareness and preventive screening are encouraged. The ability to understand cancer information is an essential health care skill and allows individuals to engage in meaningful conversation with providers to assess their risk of disease and agree on best practices appropriate to the determined risk. ${ }^{23,24}$ The need for shared decision making is most compelling in cancer care where numerous treatment options exist, and where different benefits and risks must be evaluated under conditions of uncertainty. ${ }^{25}$ As a component of decision making, risk comprehension involves the ability to judge the severity of potential harm which, in turn, depends on understanding the health message and numeric risk estimates. ${ }^{26}$

Other factors which likely affect numeracy skill are participants' levels of math anxiety ${ }^{27}$ and the level of attained education. Risk comprehension skill is also influenced by prior experience and familiarity of information. ${ }^{8,28-30}$ Risk comprehension

Author References

1 Faculty of Health Sciences University of Western Ontario London, ON

2 Department of Health Studies and Gerontology Faculty of Applied Health Sciences University of Waterloo, Waterloo, ON

Correspondence: Laurie Hoffman-Goetz Department of Health Studies and Gerontology, Faculty of Applied Health Sciences, University of Waterloo,

200 University Avenue West, Waterloo, ON N2L 3G1, Fax: 519-746-2510, Email: Ihgoetz@healthy.uwaterloo.ca 
proficiency may reflect a familiarity with terms and concepts associated with risk that constitute specialized content vocabulary. ${ }^{31-32}$ Assorted health care experiences can also provide context from which the individual can draw upon in order to enhance comprehension of the intended health care message.

With Canadians increasingly using the Internet as an access point to health care information, ${ }^{22}$ the purpose of this study was to determine the influence of prose literacy skill, general- and health-context numeracy skill, math anxiety, level of attained education and familiarity of subject matter on older adults' ability to understand Internet-based cancer risk information.

\section{Methods}

\section{Participants and procedures}

A convenience sample of 140 older adults was recruited from Southern Ontario communities. For study inclusion, participants were required to: (1) be 50 to 90 years of age, (2) reside independently within the community, and (3) read and comprehend English. Individuals volunteered for participation with the awareness that they would be required to read English-language information pertaining to health issues. Participants were excluded if they had been diagnosed with any type of cancer. Request for participation was publicized at regional public libraries, community seniors' centres and through advertisements in local newspapers. Eligible participants were asked to commit to one face-to-face interview session with an estimated participant burden of 60 to 90 minutes. Public transportation was available at each interview site and each location was wheelchair accessible. The first part of the interview involved collecting demographic details from the participants, as well as scores on functional health literacy, ${ }^{33}$ general-context numeracy, ${ }^{10}$ health-context numeracy ${ }^{9}$ and math anxiety. ${ }^{34}$ The second part of the interview assessed participants' comprehension of online colorectal cancer information. Participants were offered a $\$ 40.00$ stipend as reimbursement for miscellaneous costs.

Functional health literacy was assessed using the Short Test of Functional Health Literacy for Adults (STOFHLA). ${ }^{33}$ This assessment consists of 36 prose multiplechoice questions and 4 numeracy questions. Correct responses on each of the prose and numeracy questions are assigned 2 and 7 points respectively, with a maximum score of 72 for the prose subscale and a maximum score of 28 for the numeracy subscale. A score from 0 to 55 indicates inadequate functional health literacy reflective of individuals who often misread very simple materials. Scores between 56 to 66 indicate marginal health literacy and scores between 67 to 100 indicate adequate skill. ${ }^{33}$ The STOFHLA has good internal consistency, reliability (Cronbach's $\alpha=$ 0.98) and validity compared with TOFHLA $\left(r_{s}=0.91\right)$ and the Rapid Estimate of Adult Literacy in Medicine (REALM) $\left(r_{s}=0.80\right) .{ }^{33}$

General context numeracy was assessed using a three-question general context numeracy assessment. This instrument assesses the individual's concept of probability and ability to convert percentage to proportion, and vice versa. ${ }^{10,12}$ Scores range from 0 to 3 . This instrument has adequate internal consistency. ${ }^{9}$ Scores from this numeracy index are consistent with assessed National Adult Literacy Survey (NALS) quantitative literacy scores. ${ }^{35}$

Health context numeracy was assessed using an eight-item assessment. ${ }^{9}$ The scale measures participants' ability to discern differences in magnitude of health risks and perform mathematical operations using percentages and proportions contextualized to health. ${ }^{9}$ Participants score 1 point for each correct response with scores ranging from 0 to 8. Internal consistency was reasonable (Chronbach's $\alpha=0.74,0.70$ and 0.75). ${ }^{9}$

Finally, math anxiety was assessed using the Abbreviated Math Anxiety Scale (AMAS), a nine-item scale with strong internal consistency (Cronbach's $\alpha=.90$ ) and test-retest reliability $(\mathrm{r}=.85) .{ }^{36}$ Test item scores range from 1 (low anxiety) to 5 (high anxiety) with a maximum test score of 45 . The test requires participants to indicate their anxiety level in mathematicsbased situations. ${ }^{36}$

The latter part of the interview was devoted to the assessment of risk comprehension. Participants read two separate Internet articles of consumer-oriented, colorectal cancer prevention information from the Canadian Cancer Society (CCS) Web site. The Internet articles were selected for similarities in terms of the cancer type, font size and readability. Internet article selection was based on the following criteria: (1) $\geq 6$ numerical references, (2) numerical references in number or text form, (3) a maximum grade 12 reading level (determined by SMOG readability assessment), ${ }^{37}$ and (4) a maximum length of 3 pages.

Eligible Internet articles were screened by the researchers and community cancer prevention partner organizations for information judged to be "common" or "uncommon", and one article was selected to represent each of these categories. Common information included material that was widely publicized, easily accessible, and that replicated general CCS introductory information available for all cancer types. For online seekers, this single page was one of the first links within a list of colorectal cancer topics and had a grade 10 SMOG readability score.

The second Internet article focused on a less common aspect of colorectal cancer: genetics. This information, 1.25 pages in length, scored a grade 11-12 SMOG rating. Despite an increased awareness of hereditary influences on disease, public understanding of genetics is often limited..$^{38-40}$ Consequently, the CCS colorectal cancer and genetics Internet article was chosen to represent information considered uncommon to the general public. Community cancer prevention education partners contributed to Internet article selection.

Internet article information was printed on $8 \frac{1}{2}$ by 11 inch paper with 14-type font. Printed versions were used to control for the potential confound of computer skill diversity. Given the reality of Internet site updating, the printed pages ensured consistency of information over the course of the investigation.

Multiple-choice prose and numeracy questions, based on the Internet article content were used to evaluate participant comprehension of the risk information. Prose and numeracy comprehension questions were 
written at grade 8 to 9 readability. The comprehension questions were designed to capture participant understanding of the intended cancer message using health literacy (e.g. "What does incidence mean?") as well as their understanding of health numeracy (e.g. "What percentage of men died from colorectal cancer?”). The research team reviewed the comprehension test questions (contributing to face validity and content validity) and the questions were piloted with 30 older adults using their feedback for instrument revision. Participants were allowed unrestricted use of the printed Internet articles to respond to the comprehension questions. Simultaneous presentation of the two Internet articles allowed the participant to select which page to begin with.

\section{Statistical analysis}

All analyses were conducted with SPSS, Version 14.0 (SPSS, 2005). Descriptive statistics and participant scores for functional health literacy (STOFHLA), numeracy and math anxiety were summarized. Using multiple regression analysis, the authors considered the following as response variables: (1) total risk comprehension scores (2) risk comprehension scores from the common Internet article and (3) risk comprehension scores from the uncommon Internet article. Chosen a priori, explanatory variables included functional health literacy (STOFHLA), general context numeracy, health context numeracy, math anxiety and level of attained education. The explanatory variables of age, self-rated English skill, reading frequency, self-rated statistical understanding and income were included in subsequent regression modelling. Gender was kept in all regression equations regardless of statistical significance.

The non-parametric Wilcoxon Signed Ranks test was used to determine differences between common and uncommon Internet article test scores. The Mann-Whitney U test determined score differences between genders. In all analyses, a $p$ value of 0.05 was taken to indicate a difference that was unlikely to arise from chance alone.

\section{Results}

Demographic characteristics of participants

Participants ranged in age from 50 to 90 years with $65 \%$ of participants ranging from 50 to 69 years. There were more women $(\mathrm{n}=103,73.6 \%)$ than men $(\mathrm{n}=$ $37,26.4 \%)$ and the majority of participants was retired (63.6\%), well-educated $(52.9 \%$ college or university degree) and at a lower annual income level ( $<\$ 35,000 ; 56.5 \%$ ). Most participants ( $n=102,72.9 \%$ ) owned a computer and had access to the Internet. Further characteristics of this convenience sample are described elsewhere. ${ }^{41}$

\section{Literacy and numeracy profiles}

Table 1 gives the range of health literacy prose skill, numeracy skill and math anxiety scores. There were no significant differences between men and women on total STOFHLA scores (Mann-Whitney $=1797.5$, $p=0.52$ ), on the STOFHLA prose score (Mann-Whitney $=1878.5, p=0.89$ ), or the STOFHLA numeracy score (Mann-Whitney $=1819.5, p=0.57)$. Men $(\overline{\mathrm{x}}=20.02,95 \%$ $\mathrm{CI}=17.71,22.35)$ had less math anxiety than women $(\overline{\mathrm{x}}=25.09,95 \% \mathrm{CI}=23.41$, 26.77) (Mann-Whitney $=1136.50, p=0.001$ ).

\section{Participant subjective risk appraisal}

Participants were asked to respond to questions assessing their subjective appraisal of risk. Almost 59\% of participants suggested that a 1 in 16 lifetime probability of developing colorectal cancer constituted a high-risk situation (response range $=$ low, medium, high). More than three quarters of participants $(76 \%)$ indicated that they would seek screening for colorectal cancer knowing that their lifetime risk for developing colorectal cancer was 1 in 14 for men and 1 in 16 for women.

Thirty percent of participants were unable to correctly list examples of first degree family members. Participants with adequate functional health literacy were better able to correctly respond to this task than those in the lower functional health literacy categories $\left(\chi^{2}=10.02\right.$, $\left.\mathrm{df}=2, p=0.004\right)$.
TABLE 1

Prose literacy, numeracy and math anxiety assessment scores

\begin{tabular}{|c|c|}
\hline Variable & $\begin{array}{l}\text { Total Mean Scores } \\
\text { (95\% Confidence Interval) }\end{array}$ \\
\hline STOFHLA prose & $\begin{array}{l}63.5 / 72 \\
(61.54,65.45)\end{array}$ \\
\hline STOFHLA numeracy & $\begin{array}{l}26.20 / 28 \\
(25.58,26.81)\end{array}$ \\
\hline Health numeracy & $\begin{array}{l}5.9 / 8 \\
(5.54,6.20)\end{array}$ \\
\hline Math anxiety & $\begin{array}{l}23.8 / 45 \\
(22.37,25.21)\end{array}$ \\
\hline STOFHLA total & $\begin{array}{l}89.7 / 100 \\
(87.47,91.93)\end{array}$ \\
\hline Variable & Total \% \\
\hline STOFHLA level & $\begin{array}{l}\text { Inadequate }=2 \\
\text { Marginal = } 7 \\
\text { Adequate = } 91\end{array}$ \\
\hline General numeracy & $\begin{aligned} 0-1 \text { correct } & =55 \\
2 \text { correct } & =29 \\
3 \text { correct } & =16\end{aligned}$ \\
\hline
\end{tabular}

\section{Risk comprehension}

The mean response score for total risk comprehension (combined common and uncommon Internet articles) was 16.8/22 (95\% CI $=16.19,17.38)$. There was no significant gender difference in risk comprehension test scores. There was a significant difference between participant scores on the common and uncommon colorectal cancer Internet articles (Wilcoxon Signed Ranks $=-7.248, p<0.01)$. Individuals scored better on the common Internetbased information (mean $=9.14,95 \% \mathrm{CI}=$ $8.85,9.44)$ than the uncommon information (mean $=7.64,95 \% \mathrm{CI}=7.25,8.03)$.

\section{Regression modelling of risk comprehension}

To assess the contributions of STOFHLA health literacy skill, general context numeracy skill, health context numeracy skill, math anxiety and attained education (a priori 
explanatory variable set) on total risk comprehension scores, a multiple regression analysis was performed (see Table 2). Controlling for gender, approximately $60 \%$ of the variation in participant risk comprehension (total scores) was accounted for by the a priori explanatory variable set of: STOFHLA prose skill, STOFHLA numeracy skill, general context numeracy skill, health context numeracy skill, math anxiety and attained education $(\mathrm{F}=27.21$, df $\left.=7, p<0.01, \mathrm{R}^{2}=0.598\right)$. Further modelling that incorporated the explanatory variables of income, self-rated English language skill, reading frequency and selfrated statistical understanding did not contribute to the final model. The final, most parsimonious regression model included STOFHLA prose skill, STOFHLA numeracy skill, health context numeracy skill and participant age, and accounted for $57 \%$ of the variance in participant risk comprehension total scores $(\mathrm{F}=35.244$, df $\left.=5, p<0.01, \mathrm{R}^{2}=0.568\right)$.

Additional regression modelling used the common and uncommon risk comprehension scores separately as response variables. Controlling for gender, $38 \%$ of the variation in risk comprehension of the common Internet-based information was accounted for by the a priori explanatory variable set $\left(\mathrm{F}=11.08\right.$, df $\left.=7, p<0.01, \mathrm{R}^{2}=0.377\right)$. Further modelling revealed that STOFHLA numeracy, health context numeracy and participant age produced the most parsimonious regression model $(\mathrm{F}=18.486$, $\left.\mathrm{df}=4, p<0.01, \mathrm{R}^{2}=0.354\right)$. No other explanatory variables significantly contributed to the regression model.

The a priori explanatory variable set accounted for $56 \%$ of the variation in risk comprehension of uncommon Internetbased colorectal cancer information $\left(\mathrm{F}=23.453, \mathrm{df}=7, p<0.01, \mathrm{R}^{2}=0.562\right)$. The most parsimonious model included STOFHLA prose skill, general-context numeracy skill, health-context numeracy skill and controlled for gender $(\mathrm{F}=34.675$, $\left.\mathrm{df}=4, p<0.01, \mathrm{R}^{2}=0.507\right)$. No other explanatory variables significantly contributed to the regression model.
Almost $60 \%$ of the variability in total and uncommon comprehension scores of cancer risk information was explained by prose and numeracy skill. Only $35 \%$ of the vari-

ation in risk comprehension of common colorectal cancer information can be attributed to numeracy skill (prose skill was not a significant predictor).
TABLE 2

Multiple regression modelling of participant comprehension of Internet-based colorectal cancer information

\begin{tabular}{|c|c|c|c|}
\hline Explanatory Variable & $\begin{array}{l}\text { Common Internet } \\
\text { Information }\end{array}$ & $\begin{array}{l}\text { Uncommon Internet } \\
\text { Information }\end{array}$ & $\begin{array}{l}\text { Combined Common } \\
\text { and Uncommon } \\
\text { Information }\end{array}$ \\
\hline & $\beta(95 \% \mathrm{Cl})$ & $\beta(95 \% \mathrm{Cl})$ & $\beta(95 \% \mathrm{Cl})$ \\
\hline Gender & $0.118(-0.44,0.67)$ & $0.30(-0.36,0.96)$ & $0.00(-0.92,0.92)$ \\
\hline Age & $-0.26(-0.53,-0.006)^{*}$ & $-0.32(-0.65,0.009)$ & $-0.678(-1.14,-0.21)^{*}$ \\
\hline STOFHLA prose & $0.014(-0.01,0.04)$ & $0.07,(0.04,0.09)^{* *}$ & $0.067(0.03,0.11)^{* *}$ \\
\hline STOFHLA numeracy & $0.087(0.02,0.16)^{* *}$ & $0.043(-0.04,0.13)$ & $0.10(-0.017,0.218)$ \\
\hline General numeracy & $-0.13(-0.39,0.14)$ & $0.58(0.28,0.89)^{* *}$ & $0.466(-0.002,0.89)$ \\
\hline Health numeracy & $0.401(0.26,0.54)^{* *}$ & $0.38(0.20,0.56)^{* *}$ & $0.838(0.60,1.07)^{* *}$ \\
\hline Math anxiety & $-0.004(-0.35,0.028)$ & $-0.006(-0.4,0.031)$ & $-0.01(-0.06,0.04)$ \\
\hline Education & $0.15(-0.12,0.43)$ & $0.21(-0.11,0.53)$ & $0.363(-0.09,0.82)$ \\
\hline Overall Model & $\mathbf{F}$ & df & R2 \\
\hline \pm Total combined & 27.21 & 7 & $0.598^{* *}$ \\
\hline$\ddagger^{1}$ Final total combined & 35.24 & 5 & $0.568^{* *}$ \\
\hline \pm Common & 11.08 & 7 & $0.377^{* *}$ \\
\hline$\ddagger^{2}$ Final common & 18.49 & 4 & $0.354^{* *}$ \\
\hline \pm Uncommon & 23.45 & 7 & $0.562^{* *}$ \\
\hline$\ddagger^{3}$ Final uncommon & 34.675 & 4 & $0.507^{* *}$ \\
\hline
\end{tabular}

Note:

$\beta=$ Beta coefficient, $\mathrm{Cl}=$ Confidence interval

* Significant at $p<0.05$

** Significant at $p<0.01$

\pm Model Variables: STOFHLA prose, STOFHLA numeracy, general numeracy, health numeracy, math anxiety and attained education

$\ddagger^{1}$ Parsimonious Final Model $=$ STOFHLA prose and numeracy, health numeracy, age

$\ddagger^{2}$ Parsimonious Final Model $=$ STOFHLA numeracy, health numeracy, age

$\ddagger^{3}$ Parsimonious Final Model $=$ STOFHLA prose, general numeracy, health numeracy (gender controlled in all models) 


\section{Discussion}

While recognizing the influence of patient characteristics (i.e., social support, health status) ${ }^{26,42}$ and presentation format (i.e., gain/loss framing, graphical vs. text) ${ }^{31,43,44}$ on risk comprehension ability, this study focused on the influence of prose and numeracy skill, math anxiety, level of attained education and information context on the ability of older Canadians to understand Internet-based colorectal cancer prevention information. While the authors found that there was adequate risk comprehension skill among older adults participating in this study, and that comprehension of common cancer-prevention information was better than comprehension of uncommon cancer-prevention information, the main findings of the study were regarding the role of health-context numeracy skill.

To our knowledge, no other published work has included risk comprehension of online cancer-prevention information using the health-context numeracy instrument. Poor general-context numeracy skill has been linked to decreased accuracy in assessing and personalizing cancer risk. ${ }^{10,11,18,20}$ Although health-context numeracy skill predicted comprehension success of both common and uncommon online colorectal cancer pages, basic (STOFHLA) numeracy ability predicted participants' comprehension of common online prevention information only. In contrast, general-context numeracy skill predicted comprehension of the more challenging or uncommon information but not comprehension of the common colorectal cancer risk information.

To demonstrate comprehension of common Internet article information, participants were required to spot, for example, the value that signifies "the risk of death from colorectal cancer for men" (i.e., 1 in 14). The STOFHLA numeracy instrument seems to be best aligned with the most basic numeracy skill category of number identification. ${ }^{41}$ Yet participants responding to common Internet article comprehension questions also required greater numeric proficiency than that required by STOFHLA (e.g. to calculate the percentage of men dying from colorectal cancer) - a skill level characteristic of the advanced categories in the health numeracy framework. ${ }^{16,45}$ Although the uncommon Internet article information also challenged participants' basic and advanced numeracy skill, STOFHLA numeracy skill was not a significant predictor. Given the lack of general public knowledge regarding genetic influences on colorectal cancer, ${ }^{39,40}$ it is possible that the basic numeracy skill was not enough, due to a lack of knowledge content regarding the genetic basis of disease. ${ }^{30}$ Established evidence has demonstrated that breadth of vocabulary and domain knowledge increased comprehension of information. ${ }^{46}$ Topic familiarity also enhances individual ability to understand risk-based information. ${ }^{8,44,47,48}$ It is not surprising that prose health literacy skill contributed only to comprehension of uncommon colorectal cancer information. The terms and phrases used within the genetic information may have required a vocabulary distinct from that needed to understand the common Internet article. Consequently, those producing health promotion messages may wish to repeat less familiar terms and include examples of key concepts. ${ }^{44}$ The interactive capabilities attributable to online health sources present an excellent avenue for unobtrusively incorporating such information props.

Not unexpectedly, older age predicted poorer comprehension scores for the combined common/uncommon risk assessment and for the common assessment but not for uncommon risk comprehension assessment scores. A recent evaluation of older adults' comprehension of Internetbased colorectal cancer information also revealed limited understanding of the intended message. ${ }^{49}$ The relationship between increased age and lower literacy and numeracy skill has been previously established. ${ }^{12,13,33}$ Current findings are consistent with international analyses of adult literacy and numeracy skill. In fact, an inverse relationship between age and literacy skill exists even after controlling for educational attainment. ${ }^{50}$ The International Adult Literacy Survey (IALS) reports educational attainment as an unreliable predictor of literacy skill. ${ }^{51}$ The authors also found that level of formal education was not a significant predictor of literacy skill in the current study. While education plays a key role in the development of individual prose and numeracy skill, evidence suggests that the relationship between education and literacy skill involves other factors (i.e., continued education, occupational experience, motivation, cognitive changes) that contribute to literacy skill acquisition, preservation and loss over the course of a lifetime. ${ }^{51}$ In fact, educational attainment as a proxy estimate of adult literacy skill can result in considerable error. ${ }^{51}$

Approximately $76 \%$ of participants indicated that they would seek screening for colorectal cancer based on an awareness of their lifetime risk. However, recent statistics show that screening for colorectal cancer among Canadian adults 50 years and older is less than $15 \% .{ }^{21}$ While recognizing the inconsistency between actual screening for colorectal cancer and the intention to be screened, the number of older adults indicating their intention to have preventive screening after reading information on colorectal cancer risk was promising. Alternatively, it was a matter of concern that $30 \%$ of participants were unable to identify examples of first degree family members from those listed in the cancer and genetics information, and that this was linked to inadequate functional health literacy skill. Indeed, this finding takes on greater importance given current screening recommendations for all first-degree family members of individuals with known genetic markers for colorectal cancer. ${ }^{21}$

In addition, personal connection to information enhances thinking about the content and promotes understanding through increased attention to the information. ${ }^{48}$ Study participants had no apparent personal threat of colorectal cancer and, therefore, may have been less inclined to attend to educational colorectal cancer messages.

\section{Limitations}

There are limitations to this study. The risk comprehension skill of seniors living independently in the community may be different from those who are ill. Illness can affect an individual's cognitive reasoning and decision-making skills, altering the ability to accurately comprehend risk information..$^{52}$ Similarly, the literacy skill of participants is not representative of younger 
Canadians. However, the higher propensity for cancer illness among older adults guided our study design. Therefore, the current findings reflect a well-, rather than a healthcompromised, group of seniors.

Selection bias is possible given that literate individuals are more likely to volunteer for a study on comprehension of health information. Individuals who did not visit the libraries or seniors' centres would have limited representation within the study. The use of a convenience sample drawn from these locations may have discouraged older adults who lacked transportation (e.g., those who cannot drive, were physically disabled). However, there was diverse representation of socio-economic status of participants, providing a cross sectional account of seniors. Hence, this convenience sample reflected a group of relatively mobile, active, older adults.

An additional limitation is the lack of psychometric validation of the properties of the general- and health-context numeracy indexes, despite widespread use by researchers in the field. ${ }^{9,10,53-55}$ Preliminary investigations reveal adequate reliability ${ }^{9}$ for both the general- and health-context numeracy instruments. Health numeracy is best described as "a work in progress". ${ }^{16}$ As a result, the three numeracy measures used in this study represented those instruments that were available at the time of study conception and were used to ensure comprehensive assessment of participants' numeracy skill.

Patient characteristics ${ }^{42}$ as well as presentation format ${ }^{31,43,44}$ influence risk comprehension ability. The authors purposefully limited their investigation of cancer risk comprehension to the areas of health literacy and health numeracy. The selection of explanatory variables was a planned response to address the gaps in the research literature on health numeracy as it relates to risk comprehension skill.

Lastly, the reading levels of the online health information scored at grade 10 and $11 / 12$. These reading grade levels were higher than the grade 5/6 readability level recommended for the general public. ${ }^{56}$ This is an important limitation in the consideration of information comprehension. Yet, participants examined the same information they would have reviewed though naturalistic and independent searching of the CCS Web site.

\section{Conclusion and implications for practice}

This research is the first to investigate the influence of health literacy skill, particularly numeracy skill, on the ability of older Canadians to comprehend online colorectal cancer-prevention information. The findings revealed that health-context numeracy skill was a consistent predictor of participant ability to comprehend risk within common as well as more challenging cancer prevention information.

Finding that participant risk comprehension was jointly facilitated by prose and numeracy skill highlights the need for clarification of terms and concepts within educational online health information. Thus, impersonal prevention messages may be enhanced by repetition of terms and detailed explanation of less familiar concepts to aid reader comprehension of the colorectal cancer-prevention information. The fact that even basic numeracy tasks may be perceived as more demanding if positioned within an unfamiliar context challenges information specialists and Web designers to construct Internet-based information to accommodate diverse health literacy skills.

There is the increasing expectation that individuals take an active role in the decisions about their health care. Continued investigation is needed to refine the concept of health numeracy, develop comprehensive numeracy assessment instruments, and further investigate the relationship between health prose and numeracy skill with all age cohorts, pertaining to various chronic illnesses, and among diverse ethnic groups.

\section{Acknowledgements}

Research supported by a grant from the Canadian Institutes of Health Research. The authors thank our community partner, the Cancer Prevention and Early Detection Network of Waterloo Region, E. Harvey for advice regarding statistical analyses, and the 140 individuals who participated in the study.

\section{References}

1. Nielsen-Bohlman L, Panzer A, Kindig DA, eds. Institute of Medicine (IOM). Health literacy: A prescription to end confusion. Washington, DC: The National Academies Press, 2004.

2. Public Health Agency of Canada (PHAC). What determines health? URL: http:// www.phac-aspc.gc.ca/ph-sp/determinants/ index-eng.php .

3. Baker DW, Gazmararian JA, Sudano J, Patterson $\mathrm{M}$. The association between age and health literacy among elderly persons. J Gerontol B Psychol Sci Soc Sci. 2000;55: S368-S374.

4. Baker DW, Gazmararian JA, Williams MV, Scott T, Parker RM, Green D, et al. Health literacy and use of outpatient physician services by Medicare managed care enrollees. J Gen Intern Med. 2004;19:215-220.

5. Baker DW, Parker RM, Williams MV, Clark WS. Health literacy and the risk of hospital admission. J Gen Intern Med. 1998;13:791-798.

6. Fuller R, Dudley N, Blacktop J. Risk communication and older people-understanding of probability and risk information by medical inpatients aged 75 years and older. Age Ageing. 2001;30:473-476.

7. Gazmararian JA, Baker DW, Williams MV, Parker RM, Scott TL, Green DC, et al. Health Literacy among medicare enrollees in a managed care organization. JAMA. 1999;281:545-551.

8. Health Canada. How does literacy affect the health of Canadians? Ottawa: Health Canada, 2003. URL: http://www.travelhealth.gc.ca/ ph-sp/literacy-alphabetisme/literacy-eng.php.

9. Lipkus IM, Samsa G, Rimer BK. General performance on a numeracy scale among highly educated samples. Med Decis Making. 2001;21:37-44. 
10. Schwartz L, Woloshin S, Black W, Welch H. The role of numeracy in understanding the benefit of screening mammography. Ann Intern Med. 1997;127: 966-972.

11. Schwartz SR, McDowell J, Yueh B. Numeracy and the shortcomings of utility assessment in head and neck cancer patients. Head Neck. 2004;26:401-407.

12. Sheridan S, Pignone M, Lewis C. A randomized comparison of patients' understanding of number needed to treat and other common risk reduction formats. J Gen Intern Med. 2003;18:884-892.

13. Williams MV, Parker RM, Baker DW, Parikh NS, Pitkin K, Coates WC, et al. Inadequate functional health literacy among patients at two public hospitals. JAMA. 1995;274: 1677-1682.

14. Wolf MS, Gazmararian JA, Baker DW. Health literacy and functional health status among older adults. Arch Intern Med. 2006;165:1946-1952.

15. Nurss J, Parker RM, Baker DW. TOFHLA: Test of Functional Health Literacy for Adults. Peppercorn Books and Press Inc. 1995.

16. Golbeck AL, Ahlers-Schmidt CR, Paschal AM, Dismuke SE. A definition and operational framework for health numeracy. Am J Prev Med. 2005;29:375-376.

17. Davids SL, Schapira M, McAuliffe TL, Nattinger AB. Predictors of pessimistic breast cancer risk perceptions in a primary care population. J Gen Intern Med. 2004; 19:310-315.

18. Sheridan SL, Pignone M. Numeracy and the medical student's ability to interpret data. Eff Clin Pract. 2002;5:35-40.

19. Woloshin S, Schwartz LM, Moncur M, Gabriel S, Tosteson AN. Assessing values for health: numeracy matters. Med Decis Making. 2001;21:382-390.

20. Weinstein ND, Atwood KA, Puleo E, Fletcher R, Colditz GA,Emmons K. Colon cancer: Risk perceptions and risk communication. J Health Commun. 2004;9: 53-65.
21. Canadian Cancer Society. Canadian Cancer Society Statistics, 2006. URL: http://www. cancer.ca.

22. Statistics Canada. Households using the Internet from home, by purpose of use. Government of Canada, 2004. URL: http:// www40.statcan.ca/101/cst01/arts52b.htm.

23. Eysenbach G. Towards the millennium of cybermedicine. J Med Internet Res. 1999:1;S1,e2.

24. Charles C, Gafni A, Whelan T. Shared decision-making in the medical encounter: What does it mean? (or it takes least two to tango). Soc Sci Med. 1997;44:681-692.

25. Charles C, Whelan T, Gafni A. What do we mean by partnership in making decisions about treatment? BMJ. 1999;319:780-782.

26. Weinstein ND. What Does It Mean to Understand a Risk? Evaluating risk comprehension. J Natl Cancer Inst Monogr. 1999; 25:15-20.

27. Ashcraft $\mathrm{MH}$, Kirk EP. The relationship between working memory, math anxiety, and performance. J Exp Psychol Learn Mem Cogn. 2001;27:157-175.

28. Speros C. Health Literacy: concept analysis. J Adv Nurs. 2004;50:633-640.

29. Wilson-Fisher J. The crucial link between literacy and health. Ann Intern Med. 2003;139:875-878

30. Riche JM, Reid JC, Robinson RD, Kardash $\mathrm{CM}$. Text and reader characteristics affecting the readability of patient literature. Read Improvement. 1991;28:287-292.

31. Kreuter MW. Dealing With competing and conflicting risks in cancer communication. J Natl Cancer Inst Monogr. 1999;25:27-35.

32. Jones CJ. CBA's that work. Assessing student's math content-reading levels. Teach Exceptional Child. 2001;34:24-28.
33. Baker DW, Williams MV, Parker RM, Gazmararian JA, Nurss J. Development of a brief test to measure functional health literacy. Patient Educ Couns. 1999;38:33-42.

34. Hopko DR, Mahadevan R, Bare RL, Hunt MK. The Abbreviated Math Anxiety Scale (AMAS): Construction, validity, and reliability. Assessment. 2003;10:178-182.

35. Schwartz LM, Woloshin S, Welch HG. Can patients interpret health information? An assessment of the medical data interpretation test. Med Dec Making. 2005;25:290-300.

36. Hopko DR. Confirmatory factor analysis of the Math Anxiety Rating Scale-Revised. Educ Psychol Meas. 2003;63:336-351.

37. McLaughlin GH. SMOG grading - a new readability formula. J Read. 1969;12: 639-649.

38. Boyd JH, Watkins AR, Price CL, Fleming $\mathrm{F}$, DeBaun MR. Inadequate community knowledge about sickle cell disease among African-American women. J Natl Med Assoc. 2005;9:62-67.

39. Richards M. Lay and professional knowledge of genetics and inheritance. Public Underst Sci. 1996;5;217-230.

40. Lanine AD, Jayaratne TE, Sheldon JP, Kardia SLR, Anderson ES, Feldbaum M, et al. Exploring the public understanding of basic genetic concepts. J Genet Couns. 2004;13:305-320.

41. Donelle L, Arocha JF, Hoffman-Goetz L. Assessing health numeracy among community dwelling older adults. J Health Commun. 2007;12: 651-665.

42. Peters E, McCaul KD, Stefanek M, Nelson W. A heuristics approach to understanding cancer risk perception: contributions from judgment and decision-making research. Ann Behav Med. 2006;31:45-52.

43. Schapira MM, Nattinger AB, McHorney CA. Frequency or probability? A qualitative study of risk communication formats used in health care. Med Dec Making. 2001; 21:459-467. 
44. Reid JC, Kardash CM, Robinson RD. Comprehension in patient literature: the importance of text and reader characteristics. Health Commun. 1994;6:327-335.

45. Ahlers-Schmidt CR, Golbeck AL, Paschal AM, Zackula R, Taylor NT. Breast cancer counts: numeracy in breast cancer information on the web. J Cancer Educ. 2006;21: 95-98.

46. Hirsch ED. Reading comprehension requires knowledge of the words and the world. 2003. URL: http://www.aft.org/pubs-reports/ american_educator/spring2003/AE_SPRNG.pdf.

47. Beier ME, Ackerman PL. Age, ability, and the role of prior knowledge on the acquisition of new domain knowledge: promising results in a real-world learning environment. Psychol Aging. 2005;20:341-355.

48. Spires HA, Donley J. Prior knowledge activation: inducing engagement with informal texts. J Educ Psychol. 1998;90:249-260.

49. Friedman, DB, Hoffman-Goetz L. An exploratory study of older adults' comprehension of printed cancer information: Is readability a key factor? J Health Commun. 2007;12:423-437.

50. Statistics Canada. Learning a living: the first results of the adult literacy and life skills survey. Ottawa and Paris: Organization for Economic Co-operation and Development, 2005. URL: http://www.statcan.ca/english/ freepub/89-603-XIE/89-603-XIE2005001.htm .

51. Statistics Canada. Building on our Competencies: Canadian Results of the International Adult Literacy and Skills Survey. Ottawa: Human Resources and Skills Development Canada, 2005. Catalogue no. 89-617-XIE.

52. Cassell EJ, Leon AC, Daufman SG. Preliminary evidence of impaired thinking in sick patients. Ann Intern Med. 2001; 134:1120-1123.
53. Woloshin, S, Schwartz LM, Black WC, Welch HG. Women's perceptions of breast cancer risk: how you ask matters. Med Dec Making. 1999;19: 221-229.

54. Schapira M.M, Davids SL, McAuliffe TL, Nattinger AB. Agreement between scales in the measurement of breast cancer risk perceptions. Risk Anal. 2004;24: 665-673.

55. Estrada C, Martin-Hryniewicz M, BarnesHiggs V, Collins C, Byrd JC. Anticoagulant patient information material is written at high readability levels. Stroke. 2000; 31:2966-2970.

56. Estey A, Musseau A, Keehn L. Comprehension levels of patients reading health information. Patient Educ Couns. 1991;18: 165-169. 